\title{
Assessment of Immunization Status, Coverage and Determinants among under 5-Year-Old Children in Owerri, Imo State, Nigeria
}

\author{
Chukwuma B. Duru1*, Anthony C. Iwu2 ${ }^{2}$ Kenechi A. Uwakwe1, Kevin C. Diwe1, \\ Irene A. Merenu1, Chima A. Emerole3, Chioma A. Adaeze4, Chinwe U. Onyekuru1, \\ Obinna Ihunnia ${ }^{1}$ \\ ${ }^{1}$ Department of Community Medicine, Imo State University, Owerri, Nigeria \\ ${ }^{2}$ Department of Community Medicine, Imo State University Teaching Hospital, Orlu, Nigeria \\ ${ }^{3}$ Department of Medical Services, Federal University of Technology, Owerri, Nigeria \\ ${ }^{4}$ Rico Pharmaceutical Industries, Onitsha, Nigeria \\ Email: *duruchukwuma16@yahoo.com
}

Received 19 May 2016; accepted 12 June 2016; published 15 June 2016

Copyright (C) 2016 by authors and OALib.

This work is licensed under the Creative Commons Attribution International License (CC BY). http://creativecommons.org/licenses/by/4.0/

(c) (i) Open Access

\section{Abstract}

Background: Immunization coverage in different parts of the country varies widely despite efforts to improve the services. The immunization status of children is dependent on the dynamics of vaccination uptake which is complex and involves the interplay of different associated factors. Aim: To determine the immunization coverage, status and the determinants in under 5-year-old children in Owerri municipal, Imo State. Methods: The study was a community based cross-sectional study involving 420 women and 743 under 5-year-old children. A multistage sampling technique was employed and data were collected using a pretested, semi structured interviewer administered questionnaire. Data were analysed using a computer software SPSS-IBM version 20. Results: It revealed that $63.6 \%$ and $88.9 \%$ of children less than 12 months and between $12-59$ months respectively according to households were fully immunized. The bivariate analysis showed statistically significant associations between the immunization status of the children and place of birth delivery $(p<0.0001)$, maternal age $(p<0.0001)$, level of maternal education $(p<0.01)$, level of maternal knowledge $(p<0.0001)$, religion $(p<0.05)$ and ethnicity $(p<0.01)$. Significant predictors of being fully immunized were; maternal age 25 - 29 years old $(O R=2.1)$, children aged 12 59 months $(O R=4.6)$, mother having tertiary education $(O R=5.4)$, being a Christian Catholic $(O R=12.5)$, hospital births $(O R=25.2)$ and good level of maternal knowledge $(O R=37.7)$. Conclusion: Immunization coverage is relatively high but not optimal among the studied population and thus there is a need to develop strategies aimed at achieving full immunization coverage as this is critical in the reduction of childhood morbidity and mortality.

\footnotetext{
${ }^{*}$ Corresponding author.
}

How to cite this paper: Duru, C.B., Iwu, A.C., Uwakwe, K.A., Diwe, K.C., Merenu, I.A., Emerole, C.A., Adaeze, C.A., Onyekuru, C.U. and Ihunnia, O. (2016) Assessment of Immunization Status, Coverage and Determinants among under 5-Year-Old Children in Owerri, Imo State, Nigeria. Open Access Library Journal, 3: e2753. http://dx.doi.org/10.4236/oalib.1102753 


\title{
Keywords
}

\section{Immunization Status, Under 5 Year Olds, Determinants, Owerri, Nigeria}

\author{
Subject Areas: Immunology
}

\section{Introduction}

Immunization, through the administration of a vaccine is a proven cost effective process of protecting vulnerable populations from life threatening infectious diseases. According to World Health Organization (WHO), children are fully immunized when they have received one dose of Bacillus Calmette Guerin (BCG), three doses of diphtheria, pertussis and tetanus toxoid (DPT), three doses of polio and one dose of measles vaccination within one year of a child's age [1].

Though vaccination coverage globally has been stable with immunization preventing 2 - 3 million deaths yearly, it has been estimated that about 19 million infants are not accessing basic vaccines due to peculiar regional challenges such as inadequate funds and manpower for vaccine procurement, distribution, monitoring and supervision activities, and also the poor state and management of health care facilities [2]. In 2014, 60\% of the estimated 19 million children not accessing the basic vaccines live in 10 countries of which Nigeria is one of them [3].

In Nigeria, vaccine preventable deaths accounted for about $40 \%$ of all under five deaths which was probably associated with the performance of routine immunization falling from 74\% in 2010 to 52\% in 2012 as assessed by the DPT3 coverage, a key performance indicator [3]. At the same time, OPV3coverage was observed to be rising steadily probably due to the targeted frequent National Immunization campaigns which eventually culminated to WHO declaring Nigeria in 2015 a non-endemic country for wild polio virus [3] [4].

The Nigerian National Immunization Coverage Survey 2010, using DPT3 coverage as key indicator of routine immunization reported that North Eastern region of Nigeria had the least immunization coverage of $46 \%$ while the South Eastern region had the highest coverage of $91 \%$ and this marked disparity has remained so with only about 50\% of the Nigerian States in 2012 having immunization coverage of more than $80 \%$ with Imo State (study area) in the South Eastern region falling within that category [3].

The National Demographic Health Survey (NDHS) 2013 assessed the Country's full immunization status i.e. the number of children aged 12 - 23 months who have received one dose of BCG and measles and three doses of DPT and OPV reported that only $25 \%$ of the children were fully immunized in Nigeria ranging from $10 \%$ in the North Western region and in some parts of the North as low as 2\% to 52\% in the South Eastern region of Nigeria with Imo State having the highest full immunization coverage of 62\% [5] [6].

This inequitable access to immunization services in Nigeria, further highlights the fact that the vaccination coverage or administration is not only dependent on the country's provision of vaccine supplies, equipment and manpower which the Government appears to be investing resources but also on other factors such as knowledge, opinions and attitude of mothers, mothers education, mother's religion, number of children within the family, perceived health institution support, family income, being born in a health facility and the accessibility to health facility's immunization services, lack of confidence and trust in the health services and political problems [7]-[15]. Thus, the aim of this study was to assess the immunization status, coverage, and determinants among under five-year-old children in households in Owerri Municipal, Imo State, Nigeria.

\section{Methodology}

\subsection{Study Area}

The study was conducted among households within communities in Owerri municipal Local Government Area of Imo State, South East, Nigeria. Owerri municipal is one of the three Local Government Areas that make up Owerri the capital of Imo State. It is predominantly an urban area covering about 58sq $/ \mathrm{km}$ with an estimated population of 127,213 according to the 2006 census [16]. Owerri municipal is made up of 5 communities and 15 council wards. 


\subsection{Study Population/Study Design/Selection Criteria}

The study population comprised of households with children under the age of 5 years old and their mothers from the selected study communities in Owerri municipal Local Government Area (LGA). The study was a community based cross-sectional survey carried out among 420 households and 743 under 5 year old children. Any household without an under 5-year-old child was excluded from the study and also excluded were households where the mothers were not available as at the time of the survey.

\subsection{Sample Size Estimation}

The minimum sample size was calculated using the Cochrane formula [17].

$$
n=\frac{Z^{2} p q}{d^{2}}
$$

When $n=$ minimum sample size, $Z=$ Standard normal deviate corresponding to $5 \%$ significant level, $p=$ prevalence in previous studies (62\%) [6], $q=1-p, d=$ precision set at 0.05 . $\mathrm{Z}=1.96, p=0.62, q=1-0.62$. Appling the formula above the calculated minimum sample size was 362. Thus, a sample size of 420 households was used in this study taking into consideration an attrition rate of $15 \%$.

\subsection{Sampling Technique}

The sampling technique used to select households was the multistage sampling technique. The first stage involved the selection of 3 communities from the 5 communities that make up Owerri municipal LGA using simple random sampling by balloting. The second stage involved the selection of 2 council wards from each of the communities using simple random sampling by balloting i.e. 6 council wards from the 3 communities were selected. The third stage involved the selection of enumeration areas from the council wards. Two enumeration areas from each of the six wards were selected using simple random sampling by balloting. In each enumeration area, a prominent location was identified and moving in a particular direction, each consecutive household was enrolled until 35 households with at least an under-five were selected from each enumeration area. Any household without a child under the age of 5 years was skipped and any household that had at least a child under the age of 5 years but the mother was not available to be interviewed was also skipped.

\subsection{Data Collection and Analysis}

Data was collected with a pretested, semi structured, interviewer administered questionnaire. The questionnaire comprised 3 sections; section one: the socio-demographic characteristics, section two; the immunization status of the children and section three; the factors affecting immunization coverage. Two research assistants were trained for 2 days and they helped in data collection. Data was collected from the mothers by face to face interview and information about child immunizations were collected from immunization cards and the mother's verbal report with the verification of the presence of a BCG scar. The level of knowledge of mothers about immunization was assessed depending on the number of vaccines they were able to mention. Those who could not mention any type had poor knowledge, 1 - 2 types had fair knowledge, 3 - 4 types had moderate knowledge and $>4$ types had good knowledge.

Data was cleaned and validated manually, and analysed using Statistical Package for Social Sciences (SPSS-IBM) version 20. Descriptive statistics (frequency tables, graphs and summary indices) were generated. Chi Square was used to test association between categorical variables while multiple logistic regression was used to determine the predictors of immunization. P value was set at 0.05 significant level.

\subsection{Ethical Considerations}

Ethical approval was obtained from the Ethics Committee of Imo State University Teaching Hospital (IMSUTHEC). Consent was gotten from their mothers before proceeding to the interviews. It was only in households where the mothers gave consent that were enrolled and studied. All authors hereby declare that the study has therefore been performed in accordance with the ethical standards laid down in the 1964 Declaration of Helsinki. 


\section{Results}

Four hundred and twenty questionnaires were administered with one questionnaire to each mother per household. All the questionnaires were completely and correctly filled with 743 children under the age of five years old enrolled.

\subsection{Sociodemographic Characteristics}

The mean age of the mothers interviewed was $29 \pm 1.4$ years with majority of them belonging to the Igbo ethnic group (96.2\%), ever married (94.3\%) in a monogamous relationship (97.4\%) and having either a secondary or tertiary education (93.1\%). More than half of the women were of the Christian catholic faith (57.9\%) and had a maximum of two children (64.8\%). Most of the under 5-year-old children enrolled, were between the ages of 9 months and 5 years old (82.2\%) and were delivered in a hospital (66.9\%) (Table 1).

\subsection{Awareness and Knowledge about Immunization}

Majority of the respondents (97.6\%) were aware of immunization with the commonest known childhood vaccine type and immunizable disease being BCG vaccine (100\%) and Tuberculosis (95.6\%), while meningococcal vaccine $(35.1 \%)$ and meningitis (44.9\%) were the least known. Commonest source of information about immunization mentioned by the mothers from hospitals and health care personnel (94.1\%) with the majority of the mothers (79.5\%) having a good level of knowledge of the vaccines (Table 2).

\subsection{Immunization Perception and Accessibility}

Majority of the mothers (97.8\%) felt that immunization was necessary and therefore accepted it but $36.6 \%$ of the mothers always required their husband's permission to immunize their child and majority (74.6\%) of their husbands accepts it while $16.1 \%$ of them claim that their husbands depended on whatever decisions on immunization their spouse took (Table 3).

About $45 \%$ of the mothers' encountered some difficulties trying to immunize their child with $43.1 \%$ of the respondents citing improper timing of immunization as the cause of the difficulties encountered. About $82 \%$ of the mothers were aware of the next immunization visit. More than half of the mothers (58.1\%) acknowledged the presence of immunization outreach services in their locality with $59.5 \%$ of the households being within 30 minutes reach to a health facility (Table 4).

\subsection{Children Immunization Status}

Generally, the majority of the under 5-year-old children (84\%) were fully immunized for age (Figure 1).

The immunization status in relation to their ages as at the time at which each vaccine should be taken showed that about $96 \%$ of the under 5-year-old children were immunized for BCG, 92\% for OPV3, 90\% for DPT3, 89\% for measles and 84\% for Yellow fever (Figure 2).

About $63.6 \%$ of children less than 12 months were fully immunized and the age of a child was significantly associated with the immunization status of the child $\left(\chi^{2}=54.46, \mathrm{df}=1, p<0.0001\right)$ (Table 5).

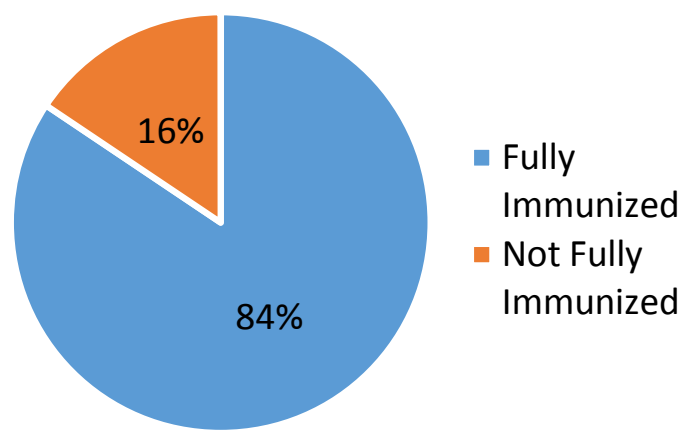

Figure 1. Children immunization status. 
Table 1. Socio-demographic characteristics.

\begin{tabular}{|c|c|c|}
\hline Variable & Category & Frequency (\%) \\
\hline \multicolumn{3}{|c|}{ Under 5 children age (months) $(n=743)$} \\
\hline & $0-11$ & $132(17.8)$ \\
\hline & $12-59$ & $611(82.2)$ \\
\hline \multicolumn{3}{|c|}{ Mothers age (years) $(n=420)$} \\
\hline & $15-24$ & $71(16.9)$ \\
\hline & $25-29$ & $173(41.2)$ \\
\hline & $30-34$ & $123(29.3)$ \\
\hline & $>35$ & $53(12.6)$ \\
\hline \multicolumn{3}{|c|}{ Marital status $(n=420)$} \\
\hline & Single & $24(5.7)$ \\
\hline & Ever married & $396(94.3)$ \\
\hline \multicolumn{3}{|c|}{ No of children per mother $(n=420)$} \\
\hline & $1-2$ & $272(64.8)$ \\
\hline & $3-4$ & 125 (29.8) \\
\hline & $>5$ & $23(5.2)$ \\
\hline \multicolumn{3}{|c|}{ Mothers occupation $(n=420)$} \\
\hline & Housewife & $114(27.2)$ \\
\hline & Student & $106(25.2)$ \\
\hline & Civil servant & $93(22.1)$ \\
\hline & Traders & $81(19.3)$ \\
\hline & Artisans & $26(6.2)$ \\
\hline \multicolumn{3}{|c|}{ Educational status of mothers $(n=420)$} \\
\hline & No education & $11(2.6)$ \\
\hline & Primary & $18(4.3)$ \\
\hline & Secondary & $175(41.7)$ \\
\hline & Tertiary & $216(51.4)$ \\
\hline \multicolumn{3}{|c|}{ Religion $(n=420)$} \\
\hline & Catholic & $243(57.9)$ \\
\hline & Orthodox & $94(22.4)$ \\
\hline & Pentecostal & $78(18.6)$ \\
\hline & Islam/Traditional & $5(1.1)$ \\
\hline \multicolumn{3}{|c|}{ Ethnic group $(n=420)$} \\
\hline & Igbo & $404(96.2)$ \\
\hline & Non Igbo & $16(3.8)$ \\
\hline \multicolumn{3}{|c|}{ Place of birth/delivery $(n=420)$} \\
\hline & Hospital & 281 (66.9) \\
\hline & Health centre & $72(17.4)$ \\
\hline & Maternity centre & $59(14.0)$ \\
\hline & Others & $7(1.7)$ \\
\hline \multicolumn{3}{|c|}{ Family type $(n=420)$} \\
\hline & Monogamous & $409(97.4)$ \\
\hline & Polygamous & $11(2.6)$ \\
\hline
\end{tabular}


Table 2. Awareness and knowledge about immunization among respondents.

\begin{tabular}{|c|c|c|}
\hline Variable & Category & Frequency $(\%)$ \\
\hline \multicolumn{3}{|c|}{ Awareness about immunization (420) } \\
\hline & Yes & $410(97.6)$ \\
\hline & No & $10(2.4)$ \\
\hline \multicolumn{3}{|c|}{${ }^{* *}$ Awareness about childhood vaccine type $(n=410)$} \\
\hline & BCG & $410(100)$ \\
\hline & Measles & $390(95.1)$ \\
\hline & DPT & $383(93.4)$ \\
\hline & OPV & $374(91.2)$ \\
\hline & HPV & $365(89.0)$ \\
\hline & Yellow fever & 352 (85.9) \\
\hline & Tetanus toxoid & 298 (72.7) \\
\hline & IPV & $204(49.8)$ \\
\hline & Meningococcal & $144(35.1)$ \\
\hline \multicolumn{3}{|c|}{${ }^{* *}$ Awareness about childhood immunizable diseases $(n=410)$} \\
\hline & Tuberculosis & $392(95.6)$ \\
\hline & Tetanus & $376(92.7)$ \\
\hline & Yellow fever & 335 (81.7) \\
\hline & Poliomyelitis & $328(80.0)$ \\
\hline & Whooping cough & 299 (72.9) \\
\hline & Diphtheria & $294(71.7)$ \\
\hline & Hepatitis & $287(70.0)$ \\
\hline & Meningitis & $184(44.9)$ \\
\hline \multicolumn{3}{|c|}{ Level of knowledge $(n=420)$} \\
\hline & Poor (none) & $10(2.4)$ \\
\hline & Fair $(1-2)$ & $14(3.3)$ \\
\hline & Moderate (3 - 4) & $62(14.8)$ \\
\hline & Good $(>4)$ & $334(79.5)$ \\
\hline \multicolumn{3}{|c|}{${ }^{* *}$ Sources of knowledge $(n=410)$} \\
\hline & Hospital personnel & $386(94.1)$ \\
\hline & Television & $214(52.2)$ \\
\hline & Radio & $170(41.5)$ \\
\hline & Friends/Relatives & $160(39.0)$ \\
\hline & Books & $62(15.1)$ \\
\hline & August meeting & $53(12.9)$ \\
\hline & Newspaper & $44(10.7)$ \\
\hline & Others & $5(1.2)$ \\
\hline
\end{tabular}

${ }^{* *}=$ multiple response. 


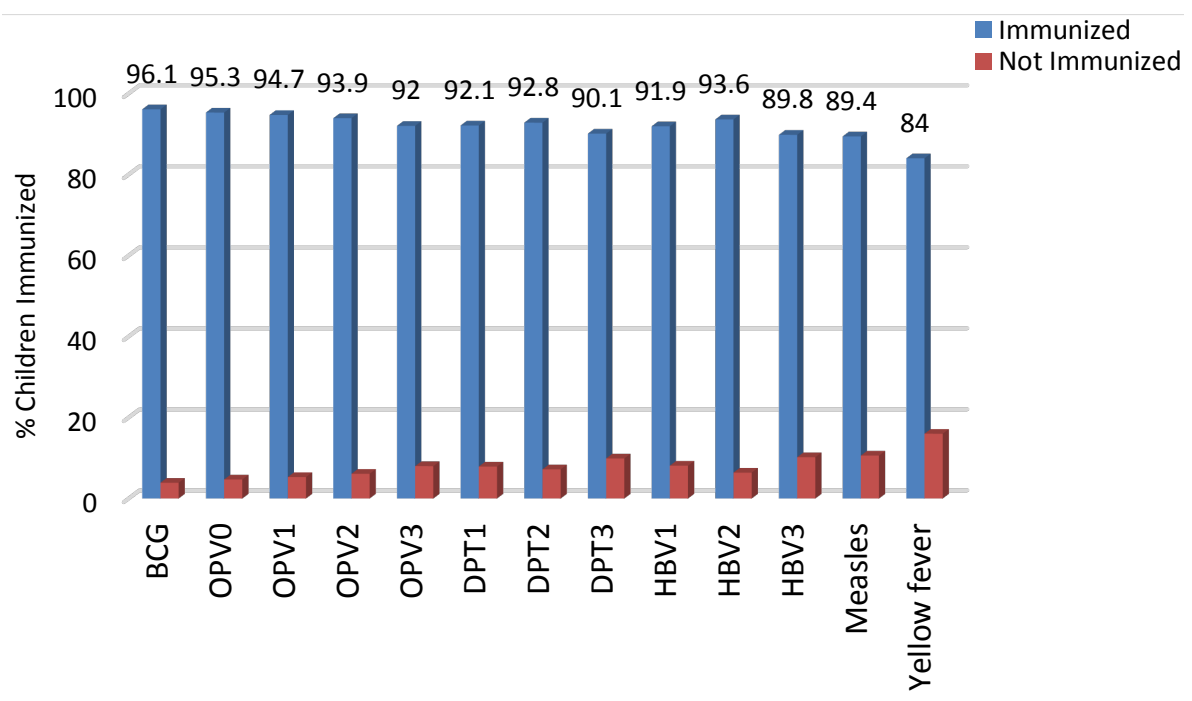

Figure 2. Immunization coverage of under 5 children by vaccine type.

Table 3. Immunization perception of mothers $(n=410)$.

\begin{tabular}{|c|c|c|}
\hline Variable & Category & Frequency (\%) \\
\hline \multirow[t]{4}{*}{ self } & Necessary & 401 (97.8) \\
\hline & Dislikes & $4(1.0)$ \\
\hline & Risky & $3(0.7)$ \\
\hline & Not necessary & $2(0.5)$ \\
\hline \multicolumn{3}{|l|}{ Husband } \\
\hline & Accepts & $306(74.6)$ \\
\hline & Depends on me & $66(16.1)$ \\
\hline & Indifferent & $26(6.3)$ \\
\hline & Skeptical & $8(2.0)$ \\
\hline & Against & $4.0(1.0)$ \\
\hline \multicolumn{3}{|c|}{ Husband's permission } \\
\hline & Yes & 150 (36.6) \\
\hline & No & $131(32.0)$ \\
\hline & Not always & 102 (24.9) \\
\hline & Not concerned & $27(6.5)$ \\
\hline \multicolumn{3}{|c|}{ Religious leaders } \\
\hline & Allows it & 243 (59.3) \\
\hline & Encourages it & 157 (38.3) \\
\hline & Skeptical & $7(1.7)$ \\
\hline & Against & $3(0.7)$ \\
\hline \multicolumn{3}{|c|}{ Community elders } \\
\hline & Necessary & 347 (84.6) \\
\hline & Not necessary & $29(7.1)$ \\
\hline & Makes children ill & $16(3.9)$ \\
\hline & For white people & $10(2.4)$ \\
\hline & Others & $8(2.0)$ \\
\hline
\end{tabular}


Table 4. Immunization accessibility.

\begin{tabular}{|c|c|c|}
\hline Variable & Category & Frequency (\%) \\
\hline \multicolumn{3}{|c|}{ Any difficulties encountered $(n=420)$} \\
\hline & Yes & $188(44.8)$ \\
\hline & No & $232(55.2)$ \\
\hline \multicolumn{3}{|c|}{${ }^{* *}$ Difficulties encountered $(\mathbf{n}=188)$} \\
\hline & Immunization timing & $81(43.1)$ \\
\hline & Vaccine availability & $59(31.4)$ \\
\hline & Hospital staff hostility & $47(25.0)$ \\
\hline & Cultural belief & $36(19.2)$ \\
\hline & Distance to health facility & $29(15.4)$ \\
\hline & Finance & $14(7.5)$ \\
\hline \multicolumn{3}{|c|}{ Distance to health facility $(n=420)$} \\
\hline & Within 30 minutes & $250(59.5)$ \\
\hline & 30 - 60 minutes & $133(31.7)$ \\
\hline & $>60$ minutes & $37(8.8)$ \\
\hline \multicolumn{3}{|c|}{ Presence of outreach services $(n=420)$} \\
\hline & Yes & $244(58.1)$ \\
\hline & No & $102(24.3)$ \\
\hline & Don’t know & $74(17.6)$ \\
\hline \multicolumn{3}{|c|}{ Awareness of time of next visit (420) } \\
\hline & Yes & $343(81.7)$ \\
\hline & No & $53(12.6)$ \\
\hline & Can’t remember & $24(5.7)$ \\
\hline
\end{tabular}

Table 5. Association between immunization status and age of child.

\begin{tabular}{|c|c|c|c|c|c|}
\hline Variable & Fully immunized freq. (\%) & Not fully immunized freq. (\%) & Total freq. (\%) & Chi-square df & p-value \\
\hline \multicolumn{6}{|c|}{ Age of child (months) } \\
\hline $0-11$ & $84(63.6)$ & $48(36.4)$ & $132(100)$ & 54.46 & $0.000^{*}$ \\
\hline $12-59$ & $534(88.9$ & $68(11.1)$ & $611(100)$ & $\mathrm{df}=1$ & \\
\hline Total & $627(84.4)$ & $116(15.6)$ & $743(100)$ & & \\
\hline
\end{tabular}

${ }^{*}=$ Statistically Significant.

\subsection{Factors Associated with the Immunization Coverage of under 5-Year-Old Children by Household}

Majority of households (73.3\%) had children that were all fully immunized by age (Figure 3).

The following sociodemographic factors were significantly associated with immunization coverage of the under 5-year-old children by household; Maternal age $(p<0.0001)$, Maternal education $(p<0.01)$, Maternal religion $(p<0.05)$, ethnicity of origin $(p<0.01)$ and place of birth delivery of the children. $(p<0.0001)$. While on 


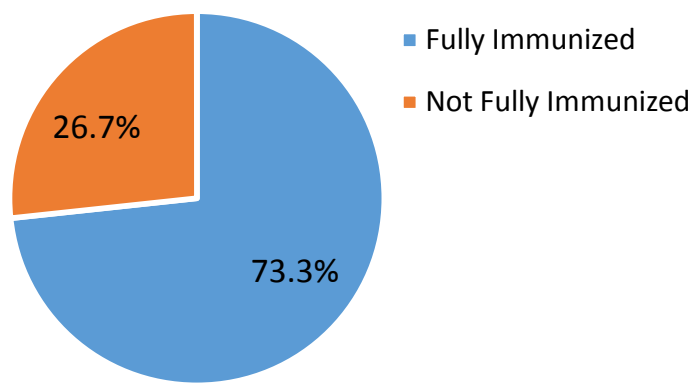

Figure 3. Immunization coverage by households.

the other hand, marital status, maternal occupation and family type were not significantly associated with immunization coverage of the children by household. $(p>0.05)$ (Table 6).

Furthermore, the level of maternal knowledge of vaccines was significantly associated with immunization coverage of the under 5 year old children by households $(p<0.0001)$ (Table 7).

\subsection{Predictors of Immunization Coverage of under 5-Year-Old Children in Households Using Multiple Regression}

Mothers aged 25 - 29 years old are more likely to fully immunize children in their households than their counterparts in other age groups (OR: 2.140; $1.1299-4.0534, p<0.01$ ) while those greater than 35 years old were the least likely to fully immunize their children (OR: 0.543; $0.2592-1.1355, p>0.05$ ). Mothers with primary education (OR: 7.500; 1.2759 - 44.0862, $p<0.05$ ) and tertiary education (OR: 5.426; 1.4701 - 20.0228, $p<0.01$ ) had the highest likelihood of fully immunizing the children in their households. Households whose religion was Islam or traditional religion had the least likelihood of fully immunizing their children when compared to other religious denominations (OR: 0.080; $0.0088-0.7314, p<0.01$ ). Under five year old children from households of non-Igbo extraction had the least likely hood of being fully immunized when compared with those in households of Igbo extraction (OR: 0.266; $0.0967-0.7328, p<0.01$ ). Children born in places of worship (church), home or in traditional birth attendant centres are the least likely to be fully immunized when compared to their counterparts born in health care settings (OR: 0.040; 0.0047 - 0.3362, $p<0.0001$ ) though the likely hood of being fully immunized increased with the increase in the level of care rendered by the health facility. Mothers/caregivers with good knowledge about immunization (OR: 37.714; 4.7472 - 299.6225, $p<0.0001$ ) and moderate knowledge (OR: 18.182; 2.1814 - 151.5473, $p<0.0001$ ) have the highest likelihood of fully immunizing their under five-year-old children in their households when compared with those with poor knowledge (Table 8).

\section{Discussion}

This study determined the immunization coverage of under 5-year-old children and assessed its determinants among the children in households. Subsequently it was revealed that $63.6 \%$ and $88.9 \%$ of children less than 12 months and children between 12 - 59 months respectively in Owerri municipal were fully immunized. Though this level of coverage among the children less than 12 months did not attain the goals of the Global Immunization Vision and Strategy (GIVS) [18] of at least $80 \%$ vaccination coverage in every district, it was similar with the Imo State immunization coverage according to the NDHS 2013 of $62 \%$ and other studies conducted in the Southern part of Nigeria which also fell short of the GIVS goal, implying that not every district or Local Government Area (LGA) within the State or outside the State, achieved the minimum $80 \%$ immunization coverage. [19] [20]. It is important to note, that the majority of children between 12 - 59 months were fully immunized and this could be explained by intensive immunization mop up activities and campaigns being organized and supported by the Government and donor agencies.

The disparities in immunization coverage across the local governments within the country, tend to reflect the immunization campaign effectiveness and exposes not only the possible variations in vaccine supply and health facilities between the local governments but also the contextual influences like the level of literacy, employment and poverty operating within these places of residence [21] [22]. In the present study, close to half of the 
Table 6. Association between Socio-demographic factors and immunization coverage by household.

\begin{tabular}{|c|c|c|c|c|c|}
\hline Variable & Fully immunized freq. (\%) & Not fully immunized freq. (\%) & Total Freq. (\%) & Chi-square df & p-value \\
\hline \multicolumn{6}{|c|}{ Mothers age (yrs) } \\
\hline $15-24$ & $49(69.0)$ & $22(31.0$ & $71(100)$ & 18.19 & \multirow[t]{5}{*}{$0.000^{*}$} \\
\hline $25-29$ & $143(82.7)$ & 30 (17.3) & $173(100)$ & $\mathrm{df}=3$ & \\
\hline $30-34$ & $87(70.7)$ & $36(29.3)$ & $123(100)$ & & \\
\hline$\geq 35$ & $29(54.7)$ & $24(45.3)$ & $53(100)$ & & \\
\hline Total & 308 (73.3) & $112(26.7)$ & $420(100)$ & & \\
\hline \multicolumn{6}{|c|}{ Mother's marital status } \\
\hline Single & $14(58.3)$ & $10(41.7)$ & $24(100)$ & 2.93 & \multirow[t]{3}{*}{0.087} \\
\hline Ever married & $294(74.2)$ & $102(25.8)$ & $396(100)$ & $\mathrm{df}=1$ & \\
\hline Total & $308(73.3)$ & $112(26.7)$ & $420(100)$ & & \\
\hline \multicolumn{6}{|c|}{ Mother's occupation } \\
\hline Housewife & $86((75.4)$ & $28(24.6)$ & $114(100)$ & 3.36 & \multirow[t]{6}{*}{0.499} \\
\hline Student & $83(78.3)$ & $23(21.7)$ & $106(100)$ & $\mathrm{df}=4$ & \\
\hline Civil servant & 65 (69.9) & $28(30.1)$ & $93(100)$ & & \\
\hline Trader & $57(70.4)$ & 24 (29.6) & $81(100)$ & & \\
\hline Artisan & $17(65.4)$ & $9(34.6)$ & $26(100)$ & & \\
\hline Total & $306(73.3)$ & $112(26.7)$ & $420(100)$ & & \\
\hline \multicolumn{6}{|c|}{ Mother's education } \\
\hline None & $4(40.0)$ & $6(60.0)$ & $10(100)$ & 11.25 & \multirow[t]{5}{*}{$0.010 * a$} \\
\hline Primary & 15 (83.3) & $3(16.7)$ & $18(100)$ & $\mathrm{df}=3$ & \\
\hline Secondary & $119(68.0)$ & $56(32.0)$ & $175(100)$ & & \\
\hline Tertiary & $170(78.3)$ & 47 (21.7) & 217 (100) & & \\
\hline Total & $308(73.3)$ & $112(26.7)$ & $420(100)$ & & \\
\hline \multicolumn{6}{|l|}{ Mother's religion } \\
\hline Catholic & $184(75.7)$ & 59 (24.3) & $243(100)$ & 8.09 & \multirow[t]{5}{*}{$0.044^{*} a$} \\
\hline Orthodox & $70(74.5)$ & $24(25.5)$ & $94(100)$ & $\mathrm{df}=3$ & \\
\hline Pentecostal & $53(67.9)$ & 25 (32.1) & 78 (100) & & \\
\hline Others1 & $1(20.0)$ & $4(80.0)$ & $5(100)$ & & \\
\hline Total & $308(73.3)$ & $112(26.7)$ & $420(100)$ & & \\
\hline \multicolumn{6}{|l|}{ Mother's ethnicity } \\
\hline Igbo & $301(74.5)$ & $103(25.5)$ & $404(100)$ & 7.44 & \multirow[t]{3}{*}{$0.006^{*}$} \\
\hline Non Igbo & 7 (43.8) & $9(56.3)$ & $16(100)$ & $\mathrm{df}=1$ & \\
\hline Total & $308(73.3)$ & $112(26.7)$ & $420(100)$ & & \\
\hline \multicolumn{6}{|l|}{ Place of delivery } \\
\hline Hospital & $227(80.8)$ & $54(19.2)$ & $281(100)$ & 31.87 & \multirow[t]{5}{*}{$0.000^{*}$} \\
\hline Health Centre & $46(63.0)$ & $27(37.0)$ & $73(100)$ & $\mathrm{df}=3$ & \\
\hline Maternity home & $34(57.6)$ & $25(42.4)$ & 59 (100) & & \\
\hline Others2 & $1(14.3)$ & $6(85.7)$ & 7 (100) & & \\
\hline Total & $308(73.3)$ & $112(26.7)$ & $420(100)$ & & \\
\hline \multicolumn{6}{|l|}{ Type of family } \\
\hline Monogamous & $300(73.3)$ & $109(26.7)$ & $409(100)$ & 0.002 & \multirow[t]{3}{*}{0.963} \\
\hline Polygamous & $8(72.7)$ & 3 (27.3) & $11(100)$ & $\mathrm{df}=1$ & \\
\hline Total & 308 (73.3) & $112(26.7)$ & $420(100)$ & & \\
\hline
\end{tabular}

${ }^{*}=$ Statistically significant, a = likelihood ratio, 1 = Islam and Traditional, 2 = church, home, traditional birth attendance. 
Table 7. Association between level of maternal knowledge and immunization coverage by household.

\begin{tabular}{|cccccc|}
\hline Variable & Fully immunized freq. (\%) & Not fully immunized freq. (\%) & Total freq. (\%) & Chi-square df & p-value \\
\hline Knowledge level & & & & & \\
\hline Poor (0) & $0(0.0)$ & $10(100)$ & $10(100)$ & 46.78 & $\mathbf{0 . 0 0 0}^{*}$ a \\
Fair $(1-2)$ & $4(28.6))$ & $10(71.4)$ & $14(100)$ & $\mathrm{df}=2$ & \\
Moderate (3 - 4) & $40(64.5)$ & $22(35.5)$ & $62(100)$ & & \\
Good (>4) & $264(79.0)$ & $70(21.0)$ & $\mathbf{4 2 0 ( 1 0 0 )}$ & \\
Total & $\mathbf{3 0 8 ( 7 3 . 3 )}$ & $\mathbf{1 1 2 ( 2 6 . 7 )}$ & & \\
\hline
\end{tabular}

*= Statistically significant, a = likelihood ratio.

Table 8. Predictors of immunization coverage of under 5 children.

\begin{tabular}{|c|c|c|c|}
\hline Variable & OR (estimate) & $95 \% \mathrm{CI}$ & p-value \\
\hline \multicolumn{4}{|l|}{ Age of mothers (yrs) } \\
\hline $15-24$ & 1.000 & - & - \\
\hline $25-29$ & 2.140 & $1.1299-4.0534$ & $0.018^{*}$ \\
\hline $30-34$ & 1.085 & $0.5747-2.0485$ & 0.929 \\
\hline$\geq 35$ & 0.543 & $0.2592-1.1355$ & 0.102 \\
\hline \multicolumn{4}{|l|}{ Maternal education } \\
\hline None & 1.000 & - & - \\
\hline Primary & 7.500 & $1.2759-44.0862$ & $0.035^{*}$ \\
\hline Secondary & 3.188 & $0.8342-13.1789$ & 0.089 \\
\hline Tertiary & 5.426 & $1.4071-20.0228$ & $0.012^{*}$ \\
\hline \multicolumn{4}{|l|}{ Maternal religion } \\
\hline Catholics & 1.000 & - & - \\
\hline Orthodox & 0.935 & $0.5404-1.6187$ & 0.922 \\
\hline Pentecostal & 0.680 & $0.3888-1.1885$ & 0.226 \\
\hline Others1 & 0.080 & $0.0088-0.7314$ & $0.016^{*}$ \\
\hline \multicolumn{4}{|l|}{ Tribe } \\
\hline Igbo & 1.000 & - & - \\
\hline Non Igbo & 0.266 & $0.0967-0.7328$ & $0.010^{*}$ \\
\hline \multicolumn{4}{|l|}{ Place of delivery } \\
\hline Hospital & 1.000 & - & \\
\hline Health Centre & 0.405 & $0.2314-0.7097$ & $0.001^{*}$ \\
\hline Maternity & 0.324 & $0.1783-0.5869$ & $0.000^{*}$ \\
\hline Others2 & 0.040 & $0.0047-0.3362$ & $0.000^{*}$ \\
\hline \multicolumn{4}{|c|}{ Level of maternal knowledge } \\
\hline Poor (0) & 1.000 & & \\
\hline Fair $(1$ - 2) & 4.000 & $0.3776-42.3708$ & 0.341 \\
\hline Moderate (3 - 4) & 18.182 & $2.1824-151.5473$ & $0.000^{*}$ \\
\hline Good $(>4)$ & 37.714 & $4.7472-299.6225$ & $0.000^{*}$ \\
\hline \multicolumn{4}{|l|}{ Age of child (months) } \\
\hline $0-11$ & 1.000 & - & - \\
\hline $12-59$ & 4.563 & $2.9531-7.0506$ & $0.000^{*}$ \\
\hline
\end{tabular}

\footnotetext{
* = statistically significant, 1 = Islam and Traditional, 2 = church, home, traditional birth attendants.
} 
mothers were earning an income with a majority having either a secondary or tertiary education. This may explain to some extent, the level of awareness, knowledge and subsequently the positive perception observed among the majority of the mothers in this study.

Disparities have also been observed in the number of children immunized according to vaccine type and its timing [23] and similarly in this study, less children appeared to have received the third doses compared to the first doses of a three dose vaccine and also less children appeared to have received the measles vaccine at 9 months compared to BCG at birth or the OPV1 at 6 weeks according to our routine immunization schedule. This trend may be associated with the difficulties encountered by the mothers in trying to immunize their children and as a result, after receiving the first doses of a particular vaccine they become less inclined to receive the subsequent doses of that vaccine. In the present study, $45 \%$ of the mothers reported that they encountered difficulties while trying to immunize their children and about $70 \%$ of them stated that the difficulties encountered were immunization timing, vaccine availability and hospital staff hostility.

The study revealed that there was a significant association between immunization coverage by household and mothers ethnicity ( $p=0.006$ ) with $75 \%$ of the Igbo mothers having their child fully immunized as against $44 \%$ of the non- Igbo mothers. The study further showed that it was less likely for a child from a non-Igbo family to be fully immunized when compared to an Igbo family. This is consistent to a previous study that reported that children of mothers' from the Igbo ethnic group have an increased likelihood of receiving full immunization due to their high propensity for economic power which increases their socioeconomic position and therefore the likelihood of an Igbo child being fully immunized [24].

Following this explanation, it would have been expected that a mother having an occupation with its associated improvement in economic power would have a significant association with the immune status of the child but this study's finding showed that there was no significant association between maternal occupation and immune status $(p=0.499)$. This is contrary to a number of studies that showed that maternal occupation was significantly associated with a child being fully immunized [25]-[28]. This observation in the present study is probably due to the effect of gender inequities as a consequence of cultural influences in our environment i.e. lack of decision making autonomy and earning differences between the mother and her spouse [21]. Also in this study, there appears to be gap of acceptability between the mothers $(97.8 \%)$ and their spouses $(74.6 \%)$ on immunization of their children which is further compounded by the existence of gender inequities. It even becomes more challenging to the mothers when their spouse's permission is always required to immunize their children; noting that in the present study, it was observed that $37 \%$ of mothers always required spouse permission while $32 \%$ did not.

The study revealed that religion was significantly associated with the immune status of children in the household and that households whose religion was Islam or traditional religion had the least likelihood of fully immunizing their children when compared to other religious denominations. This was similarly observed in a number of studies that showed that children of mothers of the Islam faith were less likely to be fully immunized than children of Christian mothers [27] [29].

In the present study, the age of the mother was significantly associated with immune status of the children ( $p$ $<0.0001$ ) with $78 \%$ of the mothers aged between 25 - 34 years old having children that were fully immunized compared to 55\% of mothers above 35 years old. Furthermore, it was observed that mothers aged 25 - 29 years old were more likely to fully immunize children in their households than their counterparts in other age groups while mothers greater than 35 years old were the least likely to fully immunize their children when compared to mothers aged 15 - 24 years old. This is contrary to findings in previous studies showing that children of women older than 35 years old had a higher likelihood of receiving full immunization [21] [27]. The observation in this study may be explained by other factors associated with immunization status i.e. maternal education, level of immunization knowledge and awareness of the health benefits of hospital birth deliveries, which are now significantly improving among younger mothers probably due to better education of the girl child with more effective communication strategies.

In furtherance to this, the study found significant associations between maternal education $(p<0.01)$, level of maternal knowledge $(p<0.0001)$ and the immunization coverage of households. It was observed that, not only did $78 \%$ of mothers with tertiary education, $69 \%$ with either primary or secondary education or $40 \%$ with no education have children that were fully immunized but that $79 \%$ of mothers with a good level of knowledge compared to $65 \%$ of mothers with a fair to moderate level of knowledge also had children that were fully immunized in their households. The study further showed that mothers with a tertiary education and a good know- 
ledge about immunization had the highest likelihood of fully immunizing the children in their households. These findings are similar to numerous studies and this is expected, due to the fact that increased education leads to better understanding and increased level of knowledge that is associated with an increased power to make decisions and seek appropriate health care for the child [21] [25] [27] [28] [30]-[36].

Finally, this study found significant associations between the place of birth delivery $(p<0.0001)$ and the immunization coverage of children in households. It was observed that $81 \%$ of mothers that gave birth in hospital settings compared to $58 \%$ that gave birth in non-hospital settings (health/maternity centres and others) had children that were fully immunized. It was further observed, that children born in places of worship (church), home or in traditional birth attendant centres were the least likely to be fully immunized when compared to their counterparts born in health care settings; and that the likely hood of being fully immunized in the health care facility increases, with the increase in the level of care rendered by the facility. Similarly, this association with the child's place of birth has been reported in previous studies [8] [20] [25] [27] [28] [36] and in particular a study in Haiti [37] found that the use of traditional healers by mothers was negatively correlated with vaccination rates of their children. This observation in the present study, is probably as a result of the more regular maternal health education programs and immunization activities that take place in our hospital environment and this is further collaborated by the findings in the present study, that showed that $94 \%$ of the respondents reported that hospital and health personnel were their main sources of immunization knowledge.

\section{Conclusion}

Though immunization coverage in the study population is relatively high compared to that of other areas of the Country, there are still opportunities for improving its coverage and exporting the strategies that appear or would appear to improve immune coverage to other areas of the country with similar culture; as strategies that work in one area may not be as effective in another area of dissimilar culture. This will result in an equity in the focus of immunization programs which is more likely to translate to an overall higher immunization coverage. In addition to the associated factors identified, there also appear to be other opportunities to improve immune status of children in the areas of husband education, health personnel orientation and enhancing the efficiency of immunization service delivery.

\section{Limitations}

The study assessed the immune status and it associated factors in under 5-year-old children, however, the interpretation of the findings in this study is subject to the following limitations; recall bias, as some of the mothers may not recall accurately all the events that took place during immunization even though data collected was based not only on the mother's report but vaccination cards and the presence of BCG scar; of which in some cases, the vaccination cards were missing.

\section{Acknowledgements}

We thank the participants that agreed to participate in this research despite all the challenges and the research assistants who helped during the data collection.

\section{Authors' Contributions}

All the authors participated in the study.

\section{Competing Interest}

The authors hereby declare that there are no competing interests.

\section{Source of Funding}

There was no external source of funding

\section{References}

[1] World Health Organization (2005) Immunization Coverage Cluster survey Reference Manual. Immunization, Vaccines 
and Biologicals. Geneva.

[2] World Health Organization (2016) Immunization Coverage Fact Sheet No 378. Geneva. http://www.who.int/mediacentre/factsheets/fs378/en/

[3] National Primary Health Care Dev Agency (NPHCDA) (2016) National Routine Immunization Strategic Plan 20132015. http://www.jhsph.edu/research/centers-and-institutes/ivac/resources/Nigeria-NRISP-Technical-Policy.pdf

[4] World Health Organization (2016) Poliomyelitis Fact Sheet No 114. Geneva. http://www.who.int/mediacentre/factsheets/fs114/en/

[5] Doctor HV, Bairagi R, Findley SE, Helleringer S, Dahir T (2011) Northern Nigeria Maternal, Newborn and Child Health Programme: Selected Analyses from Population-Based Baseline Survey. The Open Demography Journal, 4, 1121. http://dx.doi.org/10.2174/1874918601104010011

[6] National Population Commission (NPC) Nigeria and ICF Macro, 2014. Nigerian Demographic and Health Survey (NDHS). 2013; Abuja Nigeria, National Population Commission and ICF Macro 2013.

[7] Matsumura, T., Nakayama, T., Okamoto, S. and Ito, H. (2005) Measles Vaccine Coverage and Factors Related to Uncompleted Vaccination among 18-Month-Old and 36-Month-Old Children in Kyoto, Japan. BMC Public Health, 5, 59. http://dx.doi.org/10.1186/1471-2458-5-59

[8] Maina, L., Karanja, S. and Kombich, J. (2013) Immunization Coverage and Its Determinants among Children Aged 12 23 Months in a Peri-Urban Area of Kenya. The Pan African Medical Journal, 14, 3. http://dx.doi.org/10.11604/pamj.2013.14.3.2181

[9] Nath, B., Singh, J.V., Awasthi, S., Bhushan, V., Kumar, V. and Singh, S.K. (2007) A Study on Determinants of Immunization Coverage among 12 - 23 Months Old Children in Urban Slums of Lucknow District, India. Indian Journal of Medical Sciences, 61, 598-606. http://dx.doi.org/10.4103/0019-5359.37046

[10] Henoke, T., Amare, D. and Mirkuzie, W. (2009) Predictors of Defaulting from Completion of Child Immunization in South Ethiopia, May 2008-A Case Control Study. BMC Public Health, 9, 150. http://dx.doi.org/10.1186/1471-2458-9-150

[11] Belachw, E. and Wakgari, D. (2012) Factors Associated with Complete Immunization Coverage in Children Aged 12 23 Months in Ambo District, Central Ethiopia. BMC Public Health, 12, 566. http://dx.doi.org/10.1186/1471-2458-12-566

[12] Ophori, E.A., Tula, M.Y., Azih, A.V., Okojie, R. and Ikpo, P.E. (2014) Current Trends of Immunization in Nigeria: Prospect and Challenges. Tropical Medicine and Health, 42, 67-75.

[13] Oluwadare, C. (2009) The Social Determinant of Routine Immunization in Ekiti State of Nigeria. Studies on EthnoMedicine, 3, 49-56.

[14] Ankrah, V. and Nwaigwe, F. (2005) Immunization System Review and Training Needs Assessment in Ekiti State. February. Ado-Ekiti Ministry of Health. PATHS, Ado-Ekiti.

[15] Kaufmann, J.R. and Feldbaum, H. (2009) Diplomacy and the Polio Immunization Boycott in Northern Nigeria. Health Affairs, 28, 1091-1101. http://dx.doi.org/10.1377/hlthaff.28.4.1091

[16] National Bureau of Statistics (2006) Population Census Federal Republic of Nigeria. http://www.nigerianstat.gov.ng

[17] Cochran, W.G. (1963) Sampling Technique. 2nd Edition, John Wiley and Sons Inc., New York.

[18] WHO and UNICEF (2006) Global Immunization Vision and Strategy. http://www.who.int/immunization/givs/en

[19] Odusanya, O.O., Alufohai, E.F., Meurice, F.P. and Ahonkhai, V.I. (2008) Determinants of Vaccination Coverage in Rural Nigeria. BMC Public Health, 8, 381. http://dx.doi.org/10.1186/1471-2458-8-381

[20] Oyo-Ita, A., Fakunle, B., Fajola, A. and Edet, E. (2012) Immunization Coverage in Selected Communities in the Niger Delta, Nigeria. World Journal of Vaccines, 2, 21-26. http://dx.doi.org/10.4236/wjv.2012.21003

[21] Antai, D. (2012) Gender Inequities, Relationship Power, and Childhood Immunization Uptake in Nigeria: A Population-Based Cross-Sectional Study. International Journal of Infectious Diseases, 16, e136-e145. http://dx.doi.org/10.1016/j.ijid.2011.11.004

[22] Merlo, J., Chaix, B., Yang, M. and Rastam, L. (2005) A Brief Conceptual Tutorial of Multilevel Analysis in Social Epidemiology: Linking the Statistical Concept of Clustering to the Idea of Contextual Phenomenon. Journal of Epidemiology \& Community Health, 59, 443-500. http://dx.doi.org/10.1136/jech.2004.023473

[23] Central Statistical Agency Addis Ababa (2011) Ethiopia Demographic and Health Survey 2011. http://www.unicef.org/ethiopia/ET_2011_EDHS.pdf

[24] Antai, D. (2009) Inequitable Childhood Immunization Uptake in Nigeria: A Multilevel Analysis of Individual and Contextual Determinants. BMC Infectious Diseases, 9, 181. http://dx.doi.org/10.1186/1471-2334-9-181

[25] Han, K., Zheng, H., Huang, Z., Qiu, Q., Zeng, H., Chen, B. and Xu, J. (2014) Vaccination Coverage and Its Determi- 
nants among Migrant Children in Guangdong, China. BMC Public Health, 14, 203-210. http://dx.doi.org/10.1186/1471-2458-14-203

[26] Tagbo, B., Eke, C., Omotowo, B., Onwuasigwe, C., Onyeka, E. and Mildred, U. (2014) Vaccination Coverage and Its Determinants in Children Aged 11 - 23 Months in an Urban District of Nigeria. World Journal of Vaccines, 4, 175-183. http://dx.doi.org/10.4236/wjv.2014.44020

[27] Adebiyi, F. (2013) Determinants of Full Child Immunization among 12 - 23 Months Old in Nigeria. MA Thesis, University of Witwatersrand, Johannesburg. http://wiredspace.wits.ac.za/bitstream/handle/10539/13039/ADEBIYI\%20THESIS.pdf?sequence=2

[28] Hu, Y., Li, Q., Chen, E., Chen, Y. and Qi, X. (2013) Determinants of Childhood Immunization Uptake among SocioEconomically Disadvantaged Migrants in East China. International Journal of Environmental Research and Public Health, 10, 2845-2856. http://dx.doi.org/10.3390/ijerph10072845

[29] Antai, D. (2009) Faith and Child Survival: The Role of Religion in Childhood Immunization in Nigeria. Journal of Biosocial Science, 41, 57-76. http://dx.doi.org/10.1017/S0021932008002861

[30] Levine, R.A. and Rowe, M.L. (2009) Maternal Literacy and Child Health in Less-Developed Countries: Evidence, Processes, and Limitations. Journal of Developmental \& Behavioral Pediatrics, 30, 340-349. http://dx.doi.org/10.1097/dbp.0b013e3181b0eeff

[31] Animaw, W., Taye, W., Merdekios, B., Tilahun, M. and Ayele, G. (2014) Expanded Program of Immunization Coverage and Associated Factors among Children Age 12 - 23 Months in Arba Minch Town and Zuria District, Southern Ethiopia, 2013. BMC Public Health, 14, 464. http://dx.doi.org/10.1186/1471-2458-14-464

[32] Bbaale, E. (2013) Factors Influencing Childhood Immunization in Uganda. Journal of Health, Population, and Nutrition, 31, 118-129. http://dx.doi.org/10.3329/jhpn.v31i1.14756

[33] Gidado, S., Nguku, P., Biya, O., Waziri, N.E., Mohammed, A., Nsubuga, P., et al. (2014) Determinants of Routine Immunization Coverage in Bungudu, Zamfara State, Northern Nigeria, May 2010. The Pan African Medical Journal, 18, 9. http://dx.doi.org/10.11604/pamj.supp.2014.18.1.4149

[34] Obiajunwa, P.O. and Olaogun, A.A. (2013) Childhood Immunization Coverage in South West Nigeria. Sudanese Journal of Public Health, 8, 94-98.

[35] Egondi, T., Oyolola, M., Mutua, M.K. and Elungata, P. (2015) Determinants of Immunization Inequality among Urban Poor Children: Evidence from Nairobi's Informal Settlements. International Journal for Equity in Health, 14, 24. http://dx.doi.org/10.1186/s12939-015-0154-2

[36] Gupta, P., Prakash, D. and Srivastava, P.J. (2015) Determinants of Immunization Coverage in Lucknow District. North American Journal of Medical Sciences, 7, 36-40. http://dx.doi.org/10.4103/1947-2714.152076

[37] Muula, A.S., Polycarpe, M.Y., Job, J., Siziya, S. and Rudatsikira, E. (2009) Association between Maternal Use of Traditional Healer Services and Child Vaccination Coverage in Pont-Sonde, Haiti. International Journal for Equity in Health, 8, 1. http://dx.doi.org/10.1186/1475-9276-8-1 


\section{Questionnaire}

\section{Department of Community Medicine, Faculty of Medicine, College of Health Sciences Imo State University, Orlu Campus, Imo State, Nigeria \\ TOPIC: Immunization status and its determinants among under five children in households' communi- ties in Owerri Municipal LGA.} SECTION 1: BIODATA

1) Age(in years):

2) Marital status: (a) Married (

3) Number of children:

4) Occupation: (a) Civil servant ( ) (b) Housewife ( ) (c) Student ( ) (d) Farmer ( ) (e) Trader ( ) (f) Others(specify)

5) Educational status: (a) No formal education ( ) (b) Primary( ) (c) Secondary ( ) (d) Tertiary ( ) (e) Others (specify)

6) Religion: (a) Christianity (specify denomination) (b) Traditional ( ) (c) Islam ( ) (d) Others (specify)

7) Ethnicity: (a) Igbo ( ) (b) Hausa ( ) (c) Yoruba ( ) (d) Others (specify)

8) Place of delivery: (a) Traditional Birth Attendant ( ) (b) Church ( ) (c) Maternity ( ) (d) Home ( ) (e) Health centre ( ) (f) Hospital ( )

9) What type of family do you have?
(a) Nuclear i.e. me and my husband and children ( )
(b) Polygamous i.e. my husband has other wives ()
(c) Extended family ()

SECTION TWO: AWARENESS/KNOWLEDGE OF IMMUNIZATION

10)Do you know about the immunization of children?

(a) Yes ( ) (b) No ( ) (c) Somehow ()

10a) If yes, what are the immunizations given and their schedule

10b) Mention the immunizable diseases you know?

10c) Do you know the important of immunization? (Please probe)

11)How did you learn about the immunization of children?

(a) At the antenatal clinics ( ) (b) Over the radio ( ) (c) From a friend ( )

(d) Read about it ( ) (e) Others (please specify)

12)What do you think about immunizing your children?

(a) It's okay ( ) (b) it's not necessary since my children are not ill( ) (c) I don't like immunizing my children ( )

(d) it's risky and may make my child ill ( )

13)Were all your children immunized?

(a) Yes ( ) (b) No ( )

14)Must you get the permission of your husband before you take your child to be immunized?

(a) Yes ( ) (b) No ( ) (c) Not always ( ) (d) He is not concerned. ( )

15)How does your husband feel about immunization?

(a) Indifferent ( ) (b) Against it ( ) (c) Sceptical ( ) (d) The decision lies on me to make. ( )

16)What do the elderly members e.g. grandparents, of your family think about immunization?

(a) It's ok ( ) (b) It'S not important after all we didn`t have to immunize our children ( ) (c) It's for white people and we blacks don't need it. (d) It makes children ill. ( )

17)What does your village/community say about immunization?

(a) It's a taboo ( ) (b) It kills children ( ) (c) No villager should accept it ( ) (d) It is accepted. ( )

18)What does your religion say about immunization?

(a) My religion accepts it ( ) (b) It’s forbidden ( ) (c) It is artificial so forbidden ( ) (d) My

religion says nothing about it ( )

19)How does your religious leader view immunization?

(a) Allows it ( ) (b) Encourages it ( ) (c) Teaches against it ( ) (d) Sceptical ( )

20)Have you immunized your children before? Yes ( ) No ( )

If your answer is yes, help us in filling the chart below 


\begin{tabular}{|c|c|c|c|c|c|c|c|c|c|c|c|c|c|c|c|}
\hline \multirow{2}{*}{$\begin{array}{l}\text { Order of } \\
\text { children }\end{array}$} & \multirow{2}{*}{$\begin{array}{l}\text { Age of } \\
\text { child }\end{array}$} & \multirow{2}{*}{$\begin{array}{l}\text { Where was the } \\
\text { child delivered }\end{array}$} & \multirow{2}{*}{ BCG } & \multicolumn{4}{|c|}{ OPV } & \multicolumn{3}{|c|}{ DPT } & \multicolumn{3}{|c|}{$\mathrm{HBV}$} & \multirow{2}{*}{ Measles } & \multirow{2}{*}{ Yellow fever } \\
\hline & & & & 0 & 1 & 2 & 3 & 1 & 2 & 3 & 1 & 2 & 3 & & \\
\hline \multicolumn{16}{|l|}{1} \\
\hline \multicolumn{16}{|l|}{2} \\
\hline \multicolumn{16}{|l|}{3} \\
\hline \multicolumn{16}{|l|}{4} \\
\hline \multicolumn{16}{|l|}{5} \\
\hline \multicolumn{16}{|l|}{6} \\
\hline \multicolumn{16}{|l|}{7} \\
\hline \multicolumn{16}{|l|}{8} \\
\hline \multicolumn{16}{|l|}{9} \\
\hline 10 & & & & & & & & & & & & & & & \\
\hline
\end{tabular}

21)If any of your children did not complete their immunization, what caused it? I forgot ( )

Vaccine made child sick ( ) Child was sick at the time ( ) Others (specify)

22)Have you fully immunized all your children? Yes ( ) No ( ). If No, Why?

23)Did you encounter any difficulty in trying to immunize your children? Yes ( ) No ( )

If "Yes" what were the difficulties? Health care too far ( ) Fees are charged ( ) Hospital staff are hostile ( ) Vaccines don't go round ( ). Immunization schedule is inconvenient ( ) Others (specify)

\section{SECTION THREE: ACCESSIBILITY TO HEALTH FACILITY}

24)Do you have a health facility in your area? Yes ( ) No ( ) Undecided ( )

25)How long does it take to reach a health facility? $1-2 \mathrm{~km}$ ( ) $3-4 \mathrm{~km}$ ( ) $>4 \mathrm{~km}$ ( )

26)What is the means of transport to reach the health facility? By car ( ) By motorcycle ( ) By keke ( )

27)Do you have outreach immunization services in your area? Yes ( ) No ( ) Undecided ( )

\section{SECTION FOUR: UTILIZATION OF IMMUNIZATION SERVICES}

28)Are immunization services regular and reliable? Yes ( ) No ( ) Undecided ( )

29)Are immunization provided at convenient places in your area? Yes ( ) No( ) Undecided ( )

30)Are parents/care givers told when to come back for the next dose or vaccine? Yes ( ) No ( ) Undecided ( )

31)Do mothers/care givers and health workers encounter problems in the immunization program implementation? Yes ( ) No ( ). If yes, state

32)Are the rising incidence of immunizable disease in the area under study as a result of poor implementation of the program? Yes ( ) No ( )

33)Is the frequency of vaccination in the area under study adequately? Yes ( ) No ( ) 